\title{
Pilot study of the epidemiology of sports injuries and exercise-related morbidity
}

\author{
J. P. Nicholl MSc ${ }^{1}$, P. Coleman BA ${ }^{2}$ and B. T. Williams MD, FFCM ${ }^{3}$ \\ ${ }^{1}$ Senior Statistician, Mecical Research Unit, University of Sheffield Medical School, Sheffield, UK \\ 2 Research Assistant, Medical Care Research Unit, University of Sheffield Medical School, Sheffield, UK \\ ${ }^{3}$ Professor and Horiorary Director of the Medical Care Research Unit, University of Sheffield Medical School, \\ Sheffield, UK
}

\begin{abstract}
In the pilot phase of a national study of the incidence of exercise-related morbidity (ERM), funded by the Sports Council, a questionnaire about recent participation in 'active sports and other recreational activities involving vigorous physical exercise' and associated injuries or illnesses was sent to a sample of 6744 people aged 16 to 65 years in two areas. Interviews with 101 respondents were held to validate the questions. Return rates of 73 and $81 \%$ from the two areas were achieved and results from the interviews indicated that sports and injuries were being reported sufficiently accurately on the postal questionnaires to yield reliable information. Of the 4961 usable returns, a total of 1249 repondents (25\%) reported taking part in some activity in the 4 weeks before completing the questionnaire, and $137(3 \%)$ reported 158 injury incidents. Nearly half $(76,48 \%)$ of these incidents resulted in some restriction in activity, and 21 resulted in some restriction in activity, and 21 resulted in a visit to a hospital casualty department. It is estimated that nationally 1-1.5 million episodes of ERM result annually in attendance at a hospital casualty department, and 4-5 million episodes of ERM result in some, usually temporary, incapacity.
\end{abstract}

Keywords: Epidemiology, exercise rates, injury rates, population sampling, postal questionnaires

There has recently been an increase in recreational physical exercise ${ }^{1,2}$. Predominant reasons for this are increased leisure time and cultural pressures for health and fitness, or at least the appearance of fitness. There is now considerable evidence that exercise results in health benefits ${ }^{3}$, particularly with respect to coronary heart disease ${ }^{4}$, hypertension, diabetes, osteoporosis 5 , and depression 6,7 . Whether or not this evidence has promoted the trend towards physical activity, it has certainly encouraged those involved in public health programmes to recommend less sedentary lives.

The benefits of exercise must, however, be considered in the light of the associated risks both for the individuals exercising and for the community as a whole, which must bear the cost of any resulting injury and illness. Unfortunately, nothing is known

Address for correspondence: Mr J. P. Nicholl, Medical Care Research Unit, Department of Public Health Medicine, The University of Sheffield Medical School, Beech Hill Road, Sheffield S10 2RX, UK

(C) 1991 Butterworth-Heinemann Ltd. 0306-3674/91/010061-06 at present about either the individual risks or the community costs because representative national information in the UK on the incidence of exerciserelated morbidity is very limited. Hospital discharge information systems deal only with inpatient episodes. The Department of Industry's Home and Leisure Accident Surveillance Systems (HASS and LASS) data $^{8}$ are restricted to persons attending hospital Accident and Emergency (A and E) departments and thus, in effect, although they provide a large nationally representative case-series they do not enable true incidence rates to be calculated. The 1987 General Household Survey (GHS) has included questions on injuries arising from sport and exercise, but only for those injuries resulting in attendance at $A$ and $E$ departments or contact with a family doctor (general practitioner). A review of the risks of exercise $^{9}$ concluded that data permitting the calculation of incidence rates for ERM and information on how medical services are provided and apportioned among the various providers are 'essentially nonexistent'.

A national study of sports injuries and ERM in 1989-90, supported by the Sports Council of England, is therefore being undertaken, the primary objective of which is to make a national estimate of the annual incidence and seasonal patterns of ERM (on both a per capita and exposure-to-risk basis), and thus to estimate the injury risk in different subgroups of the population and for different activities. This will make it possible to identify epidemiological characteristics of the population that are risk factors for $E R M$, and hence suggest strategies for primary prevention. In addition, the study will describe the range and provision of medical services and the apportionment of treatment among them.

The national study is being conducted using a postal questionnaire sent to a random sample of the populations of 16 out of the 98 Family Practitioner Committee (FPC) areas in England and Wales. With the approval of the FPCs, local medical committees and the British Medical Association's medical ethics committee, a random sample of approximately 2500 persons aged 16-45 drawn from the FPC list in each of the selected areas is being contacted during 1989-1990. It is expected that responses from more than 1000 persons who have sustained some ERM 
will be received. The questionnaire asks about participation in sports and exercise, injuries, time off work, restriction from taking part in sports and other daily activities, and use of medical and non-medical services, as well as asking for demographic details about each respondent.

A number of issues regarding the design of the questionnaire and the approach to the sample and its selection needed to be resolved in a pilot study. This also aimed to provide an overall estimate for the injury incidence rate in typical British populations for use in designing the main study, and for making a preliminary assessment of any consequences of injury and the demand for treatment of a growing 'active ' population. The results of this pilot study undertaken in 1987 and 1988 are reported here.

\section{Methods}

A questionnaire asking about recent participation in 'active sports and other recreational activities involving vigorous physical exercise' and associated injuries or illnesses was sent ot a sample of 6744 people aged 16-65 from two FPC areas in England and Wales. One area (A) was largely urban and the other (B) largely rural.

A draft of the questionnaire was pre-piloted using a sample of 127 persons drawn at random from the Electoral Registers for the City of Sheffield and was revised in the light of the answers from 96 respondents, and comments received from the Sports Council.

Approval for the project was obtained from both the FPCs and the local medical committees. However, one FPC, in agreeing that the research using the FPC register could go ahead, required that the approach to patients should be made via the patient's GPs rather than directly by us, whenever the doctors wanted this.

\section{Sample size}

It was decided that approximately 100 persons injured in the previous 4 weeks should be identified in the pilot study. Based on activity levels reported in the 1986 General Household Survey ${ }^{1}$, and assuming that an individual who plays sport regularly might expect two, usually minor, injuries during a year, and assuming an $80 \%$ response rate, it was calculated that 8000 persons aged between 16 and 65 would need to be included in the sample. Based on these calculations, a sample size of 300 persons in each month in each area (a total of 7200 persons), was chosen.

\section{Questionnaire mailing}

In one area (A) the sampling was relatively straightforward. Each month a systematic 1/450 random sample of the names and addresses of all persons on the FPC register aged between 16 and 65 were selected and were sent the pilot study questionnaire and up to two reminders.

In the other area (B), where the patients were accessed via their GP, a two-stage sample had to be drawn. To ensure that a representative sample would be drawn throughout the year, at the beginning of the study all the GPs were allocated into monthly groups on the basis of the geographical location and list size of their practices. Each month a simple 1/666 random sample of the names and addresses of patients within the specified age range on the lists of each GP in that monthly GP sample was drawn.

Each GP in the month's sample was then sent a list containing the names and addresses of the sample of his or her patients, together with copies of the questionnaire and covering letters. Out of a total of 165 GPs on the FPC list in September 1987, only three refused to take part in the study. Each of the remaining GPs was asked to check that the names and addresses on the list were correct, to delete any patients whom should not be approached for social or medical reasons, and to indicate whether they wished to mail the questionnaires themselves, or whether mailing could be done directly by us. Thirteen $(8 \%)$ elected to mail the questionnaire themselves.

\section{Interviews with respondents}

To validate the responses to the postal questionnaires, interviews were carried out in respondents' homes in one of the FPC areas (A). On the basis of their answers to the postal questionnaire, respondents were divided into three groups:

1. Non-exercisers who reported no exercise activity during the previous year $\left(n_{1}\right.$, the number of such respondents in area $A=1685$ ).

2. Exercisers who did report exercising in the previous year $\left(n_{2}=844\right)$.

3. Exercisers reporting an exercise-related injury or illness which ocurred in the previous 4 weeks $\left(n_{3}=71\right)$.

Random samples of $115(7 \%)$ of the respondents in group 1, $66(8 \%)$ of respondents in group 2, and all those reporting an injury in the previous 4 weeks (group 3), were offered interviews. The interviews were generally held 1-2 months after receiving the questionnaire except in the case of those reporting injuries, who were interviewed on average 22 days (range 8-71) after they returned their questionnaires. One hundred and one interviews were completed altogether, 31 with reported non-exercisers, 33 with regular exercisers and 37 with regular exercisers who had reported a recent injury or illness. Nineteen of this latter group reported being treated for their injury, and they were asked at interview if we could approach their treatment providers in order to confirm details of the diagnosis and management of their injuries; 17 agreed to this.

\section{Statistical methods}

The exercise participation rates, and injury rates, reported in this study have been calculated by combining the results from the two areas using a weighted average, with weights proportional to the inverse of the achieved sampling fractions in each area (i.e. proportional to the size of the FPC population aged 16-65 divided by the number of respondents returning usable information). 


\section{Results}

\section{Response rates}

In area $\mathrm{A}$ the overall return rate was $73.2 \%$, and, discounting those questionnaires known not to have been received because they were 'Returned to sender', the nominal response rate was $80.6 \%$ (see Table 1).

In area $B$, where the GPs were asked to verify the names and addresses before the questionnaires were sent out, the return rate was $80.5 \%$ and the nominal response rate was $84.2 \%$.

In area $A$, where the age and sex of each individual in the sample was known, the return rates for men $(67 \%)$ were less than for women $(79 \%)$, and were less for younger (45 years or under) adults (71\%) than for older adults $(77 \%)$. If those questionnaires which are known not to have been received are discounted, then the nominal response rates were $74 \%$ for younger men, $80 \%$ for older men, $83 \%$ for younger women, and $86 \%$ for older women.

Table 1. Response rates

\begin{tabular}{|c|c|c|}
\hline & \multicolumn{2}{|c|}{ Area } \\
\hline & $A$ & $B$ \\
\hline $\begin{array}{l}\text { Numbers in sample sent questionnaire } \\
\text { Numbers known not to have been received } \\
\text { Nominal total received } \\
\text { Total returns } \\
\text { Total usable returns } \\
\text { Overall return rate } \\
\text { Nominal response rate* }\end{array}$ & $\begin{array}{r}3592 \\
327 \\
3265 \\
2630 \\
2620 \\
73.2 \% \\
80.5 \%\end{array}$ & $\begin{array}{r}2939 \\
131 \\
2808 \\
2365 \\
2341 \\
80.5 \% \\
84.2 \%\end{array}$ \\
\hline
\end{tabular}

* The nominal response rate is the proportion that were returned of all questionnaires sent out less those known not to have been received because they were 'Returned to sender'

\section{Exercise rates}

Of 4961 usable returns a total of 1249 respondents (25\%) reported taking part in some active sport or recreational activity involving vigorous physical exercise in the 4 weeks before completing the questionnaire. Table 2 shows the estimated (weighted) proportion of the population of the two areas who participated in various activities. The most common activities were swimming $(6.9 \%)$, keep fit $(4.5 \%)$, football $(3.7 \%)$ and running, jogging or athletics $(3.9 \%)$. The table also shows participation rates in the 4 weeks before interview reported in the 1986 GHS $^{1}$, which surveyed adults aged 16 or over in the UK.

Table 3 shows the estimated average number of occasions of participation in the last 4 weeks per participant. The activities most frequently participated in were cycling, athletics, horse-riding, and keep fit. These data agree well with those from GHS after allowing for the facts that GHS is a national sample and also actually reports the average number of days of participation rather than the number of occasions.

\section{Injury rates}

Of the 1249 respondents who reported exercising in the 4 weeks before they completed the questionnaire, $137(11 \%)$ claimed to have sustained some injury or illness. Of these, 21 had two separate injury incidents in the 4 weeks, so that a total of 158 incidents were reported. These 158 incidents involved 166 separately identified injuries: $76(48 \%)$ of the incidents resulted in participants being restricted from taking part in any of their usual activities for any length of time (restrictive injuries); and $64(41 \%)$ of the incidents resulted in treatment being sought from a third party,

Table 2. Participation rates in previous 4 weeks by type of activity*

\begin{tabular}{|c|c|c|c|c|c|}
\hline \multirow[t]{2}{*}{ Activity } & \multirow[t]{2}{*}{ Numbers } & \multicolumn{2}{|c|}{ Both areas } & \multicolumn{2}{|c|}{ GHS national survey } \\
\hline & & $\begin{array}{l}\text { Proportion } \\
\qquad \%) t\end{array}$ & $95 \% \mathrm{Cl}^{*}$ & $\begin{array}{l}\text { Activity if } \\
\text { different }\end{array}$ & $\begin{array}{c}\text { Proportion (\%) } \\
\text { participating }\end{array}$ \\
\hline \multicolumn{6}{|l|}{ Outdoor activities } \\
\hline 1 Outdoor football or unspecified & 191 & 3.7 & $(3.2,4.3)$ & Outdoor football & 2.7 \\
\hline 2 Rugby: Union, League or unspecified & 27 & 0.6 & $(0.3,0.8)$ & & 0.4 \\
\hline 3 Running, jogging or athletics & 185 & 3.9 & $(3.3,4.4)$ & $\begin{array}{l}\text { Outdoor athletics } \\
\text { or jogging only }\end{array}$ & 2.6 \\
\hline 4 Tennis & 35 & 0.7 & $(0.5,1.0)$ & & 1.4 \\
\hline 5 Cycling & 89 & 1.9 & $(1.5,2.3)$ & & 1.9 \\
\hline 6 Cricket & 26 & 0.5 & $(0.3,0.8)$ & & 0.8 \\
\hline 7 Golf & 59 & 1.3 & $(1.0,1.6)$ & & 2.7 \\
\hline 8 Horse-riding (including fox hunting) & 29 & 0.6 & $(0.4,0.8)$ & & 0.7 \\
\hline 9 Walking & 123 & 2.5 & $(2.0,2.9)$ & & 0.7 \\
\hline \multicolumn{6}{|l|}{ Indoor activities } \\
\hline 1 Squash & 126 & 2.5 & $(2.1,3.0)$ & & 2.4 \\
\hline $\begin{array}{l}2 \text { Keep fit (including aerobics, circuit training, } \\
\text { movement, exercise machines, yoga) }\end{array}$ & 220 & 4.5 & $(3.9,5.1)$ & Keep fit or yoga & 3.3 \\
\hline 3 Martial arts, etc. (excluding boxing) & 23 & 0.5 & $(0.3,0.7)$ & Self-defence & 0.4 \\
\hline 4 Badminton & 107 & 2.2 & $(1.8,2.7)$ & & 2.1 \\
\hline 5 Swimming (including outdoor) & 329 & 6.9 & $(6.2,7.7)$ & Indoor swimming & 9.5 \\
\hline
\end{tabular}

* Only activities with at least 20 respondents are shown in the Table (giving a 95\% confidence interval)

+ The proportion (\%) is a weighted estimate of the rate in the combined population of the two areas 
Pilot study of epidemiology of sports injuries: J. P. Nicholl et al.

Table 3. Average number of occasions of participation per participant in the previous 4 weeks

\begin{tabular}{|c|c|c|c|c|}
\hline Activity* & $\begin{array}{l}\text { Number of participants } \\
\text { in last } 4 \text { weeks }\end{array}$ & $\begin{array}{l}\text { Number of occasions } \\
\text { in last } 4 \text { weeks }\end{array}$ & $\begin{array}{l}\text { Averaget over } \\
4 \text { weeks }\end{array}$ & GHS \\
\hline 1 Outdoor (or unspecified) football & 187 & 935 & 4.8 & 5 \\
\hline 2 Rugby: Union or League & 27 & 126 & 4.6 & 5 \\
\hline 3 Running, jogging or athletics & 185 & 1937 & 10.5 & 9 \\
\hline 4 Tennis & 35 & 122 & 3.5 & 5 \\
\hline 5 Cycling & 91 & 971 & 10.7 & 9 \\
\hline 6 Cricket & 26 & 99 & 3.7 & 4 \\
\hline 7 Golf & 59 & 393 & 6.7 & 5 \\
\hline 8 Horse-riding & 29 & 298 & 10.3 & 7 \\
\hline 9 Squash & 126 & 596 & 4.7 & 4 \\
\hline 10 Keep fit, etc. & 20 & 2081 & 9.5 & 6 \\
\hline 11 Badminton & 107 & 461 & 4.3 & 3 \\
\hline 12 Swimming (indoor and outdoor) & 339 & 1667 & 4.8 & $3 \S$ \\
\hline 13 Martial arts etc. (excluding boxing) & 23 & 164 & 7.1 & 6 \\
\hline
\end{tabular}

* Only activities with at least 20 respondents are included in the table

$t$ This is a weighted average, with weights chosen to reflect the combined population of the two areas

\# GHS reports the average number of days of participation per 4 weeks rather than occasions

$\S$ This is the GHS figure for indoor swimming. For outdoor swimming the GHS gives an average of seven occasions per 4 weeks per participant

which was a GP, hospital doctor or hospital casualty department in $41(64 \%)$ of these cases. Because of the relatively small number of injury incidents reported in this pilot study, an analysis by type of sport cannot be made reliably. However, some comments about the epidemiology of these injuries can be made.

Of the 166 reported injuries, 49 were of an unspecified nature. In these 49 cases the respondent typically completed the section headed 'Nature of injury or illness sustained' by reporting only the site of the injury. In only seven cases was the site unknown.

Amongst the 117 injuries of a specified nature, sprains $(53,45 \%)$, particularly of the ankle $(16,14 \%)$, were the most frequent injury. Indeed, ankles were the most frequently injured part of the body (15\%), with legs $(14 \%)$, knees $(11 \%)$ and the back $(11 \%)$ the next most common.

The 'cause' of each injury incident was coded as far as possible from the brief decription of how the injury occurred which the respondents provided. We attempted from their descriptions to determine whether or not the incident had occurred 'within the

Table 4. How the injury incidents occurred

\begin{tabular}{lccc}
\hline Cause of injury & \multicolumn{3}{c}{ Nature of incident } \\
\cline { 2 - 4 } & $\begin{array}{c}\text { Within rules } \\
\text { or practices }\end{array}$ & $\begin{array}{c}\text { Outside rules } \\
\text { or practices }\end{array}$ & NK \\
\hline $\begin{array}{l}\text { Intrinsic } \\
\text { Extrinsic } \\
\text { Collision with } \\
\text { person }\end{array}$ & 86 & 1 & 2 \\
$\begin{array}{c}\text { Struck by object } \\
\text { (e.g. ball) }\end{array}$ & 26 & 6 & 3 \\
$\begin{array}{c}\text { Struck object } \\
\text { (including ground) }\end{array}$ & 10 & 2 & 1 \\
$\quad$ NK & 15 & 2 & 1 \\
All & 1 & - & 2 \\
\hline
\end{tabular}

NK, not known rules' governing the sport or activity, and whether the injury was extrinsic and the result of the subject striking or being struck by an object or being in collision with another person; or an 'intrinsic' injury, typically due to over-exertion (Table 4). Of the 158 injury incidents, $89(56 \%)$ were intrinsic, and the remaining $69(44 \%)$ extrinsic. Only 11 out of 149 incidents $(7 \%)$ appeared to have occurred outside the rules or practices of the sport or activity.

Table 5 shows injury rates for all self-reported injuries and all incapacitating injuries by age of respondent. After the age of 45 years there is a dramatic decline in the self-reported injury rate, and only ten (6.3\%) of the 158 self-reported injuries and seven $(10 \%)$ of the 70 incapacitating injuries occurred in the $1590(35 \%)$ respondents aged over 45 years. Consequently persons aged over 45 are excluded from the main study.

The treatment providers in all 158 incidents are shown in Table 6. In only 21 incidents was treatment sought from hospital casualty departments, and in 29 from family doctors.

\section{Validation of responses}

Of the 31 people who were interviewed who, in their questionnaires, had reported no sports exercise or vigorous activities in the previous 4 weeks, only five $(16 \%)$ on being shown a comprehensive list of activities at the interview subsequently reported any participation. These five reported exercising at home to keep fit, cycling, table-tennis, horse-riding, swimming, canoeing and one person reported playing football once a week.

Similarly, of the 33 persons interviewed who had reported participating in some sport or exercise, 12 $(36 \%)$ claimed at the interview to have taken part in some additional activity that they had not recorded. However, of these 12 only five reported any additional activity other than walking or hiking, swimming or cycling and one of these included going 
Pilot study of epidemiology of sports injuries: J. P. Nicholl et al.

Table 5. Sports and exercise injury rates in the previous 4 weeks by age

\begin{tabular}{|c|c|c|c|c|c|c|}
\hline \multirow[t]{2}{*}{$\begin{array}{c}\text { Age } \\
\text { (years) }\end{array}$} & \multirow[t]{2}{*}{ Respondents } & \multirow[t]{2}{*}{ Exercisers ${ }^{*}$} & \multirow[t]{2}{*}{$\begin{array}{l}\text { All self-reported } \\
\text { injury incidents }\end{array}$} & \multirow{2}{*}{$\begin{array}{l}\text { Restrictive } \\
\text { injury } \\
\text { incidents }\end{array}$} & \multicolumn{2}{|c|}{$\begin{array}{l}\text { Estimatedt injury incident } \\
\text { rates per } 100 \text { persons }\end{array}$} \\
\hline & & & & & $\begin{array}{l}\text { All injury } \\
\text { incidents }\end{array}$ & $\begin{array}{c}\text { Restrictive } \\
\text { injury } \\
\text { incidents }\end{array}$ \\
\hline $16-25$ & 991 & 413 & 54 & 29 & 5.2 & 2.9 \\
\hline $26-35$ & 1084 & 352 & 64 & 28 & 6.0 & 2.6 \\
\hline $36-45$ & 1072 & 272 & 30 & 12 & 2.8 & 1.1 \\
\hline $46-55$ & 822 & 121 & 5 & 4 & 0.6 & 0.5 \\
\hline $56-65$ & 768 & 77 & 5 & 3 & 0.9 & 0.4 \\
\hline Not known & 224 & 14 & - & - & - & - \\
\hline All ages & 4961 & 1249 & 158 & 76 & 3.2 & 1.5 \\
\hline
\end{tabular}

* Exercise habits of 158 respondents were not known

+ Injury incident rates are weighted estimates for the population of the two areas combined

out 'disco dancing'. The other four had taken part in table-tennis, weight-training, exercising on an exercise bike, keep fit, rounders, and volley-ball.

Overall, the evidence suggests that most of the more popular active sports were fully reported by respondents answering the exercise question with the possible exceptions of swimming, table-tennis, and cycling.

The 33 participants who were interviewed who claimed not to have been injured were pressed at the interview about any injury or illness, however minor, which they sustained whilst exercising in the 4 weeks before completing the questionnaire. Seven $(21 \%)$ of these reported some injury or illness. In three cases the respondent was not certain that the injury or illness was the result of the activity. Two had the recurrence of old problems which had never cleared up; one regarded the injury (strained arm muscles) as a 'hazard of the activity' (climbing); and one had simply thought the slight ankle sprain sustained while running as too trivial to report.

With the consent of those interviewed, 17 treatment providers were approached for confirmation of information given on questionnaires and at interview, and 15 responded. In $12(80 \%)$ the provider, the nature and site of the injury, and the fact that it was a sports injury was confirmed. In three cases, A and $E$ department records did not confirm the statements of patients on their questionnaires. In one case the attendance at an $\mathrm{A}$ and $\mathrm{E}$ department and the nature and site of the injury were confirmed but the

Table 6. Treatment providers 158 injury incidents

\begin{tabular}{lcr}
\hline Treatment provider & Frequency & $\%$ \\
\hline Treated & & \\
General practitioner & 29 & 36 \\
Accident and Emergeny Department & 21 & 26 \\
Physiotherapist & 15 & 19 \\
Other & 15 & 19 \\
All treated & 80 & 100 \\
Self treated & 4 & \\
Not treated & 90 & \\
All & $174^{*}$ & \\
\hline
\end{tabular}

* Sixteen incidents treated by more than one provider department had recorded a different cause of injury. In the remaining two cases no record of attendance at the stated A and E department could be found. However, in both cases the interviewer believed that the respondent had attended a casualty department.

\section{Discussion and conclusions}

The validity of surveys based on mailed questionnaires depends upon the return rates achieved and upon the (content) validity of the questions. Potential biases due to non-return can be investigated by identifying who the non-returnees are; potential inaccuracies due to the invalidity of questions can be studied by interviewing a sample of respondents to validate their responses; and the effect of both non-return and invalid questions can be investigated jointly by making population estimates based on the sample responses which can be checked against any known population values.

The extent of any non-return bias in the pilot study reported here is limited by the fact that return rates of $73 \%$ and $80 \%$ in the two areas were achieved, with about a half the non-return rate due to non-receipt and the other half due to non-response. However, we did find that men and younger persons were less likely to return questionnaires than women and older persons largely due to non-receipt. Whilst this may of course affect the estimated exercise participation rates, it is less likely to cause any bias or distortion in estimates of injury rates amongst exercisers. Furthermore, in the main study currently under way the age and sex of each individual in the sample is known and so post-sample stratification and reweighting to take account of any age and sex non-return bias can and will be made.

The possibility of using either the electoral roll or the post-office postcode address file $(\mathrm{PAF})^{10}$, which is a list of all addresses in the country to which mail is delivered, to lessen the problem of non-receipt was considered. Neither option is suitable. There is no indication of the age of any individual listed on the electoral roll nor of the age composition of households in PAF and so questionnaires would be sent to all adults aged over 17 years. Furthermore, using 
either sampling frame would result in some disabled, ill, recently bereaved, and even dead people being sent questionnaires, causing unnecessary distress.

Turning to bias due to the joint effects of non-response and question validity, the sport and exercise participation rates estimated from this pilot study compare well with those reported in the 1986 national GHS sample. Such a comparison is, however, complicated by the fact that participation in sporting activities is very strongly related to age, sex and socioeconomic status. Furthermore, there are substantial regional differences in sports participation $^{11}$ which, together with regional differences in socioeconomic conditions, makes it difficult to compare a sample from just two areas with a national sample such as the GHS. Nevertheless, some points can be made. Firstly, the participation rates were of about the right order, and for some groups they corresponded exactly to the GHS results. However, taking the GHS participation rates as a standard there is some suggestion that the more active sports (e.g. squash, football) and those 'recreational activities involving vigorous physical exercise' (e.g. keep fit) were more frequently reported than less active sports (golf) and less sport-like activities (cycling, swimming, ice-skating). This suggests that any biases were not due to non-return, but due to a differential response to the wording of the exercise question which may have been more readily eliciting active sports than other activities involving exercise.

This was confirmed in the follow-up interviews where it was found that amongst 64 uninjured respondents who were interviewed, 17 reported some additional activity that they had not listed on their postal questionnaires. However, in nearly all instances those were the less 'sport-like activities' such as keep fit, swimming, hiking and cycling. Of course, whether or not these activities are readily recognized as sports, they are activities which confer cardiorespiratory benefits and should be included in the main study. Accordingly, we slightly modified the wording of the question dropping the reference to 'vigorous' activities and including reference to 'fitness activities'. The question now asks about participation in 'any active sport or other recreational or fitness activity involving physical exercise'.

Turning to the question of the injuries, it was clear from the interviews that where a full description has been provided on the questionnaire, injuries were being reliably reported. The follow-up of treatment providers largely confirmed the details provided by 15 respondents, although there was some question about the accuracy of recording attendance at A and $E$ departments.

On the basis of the 21 self-reported attendances at $A$ and $E$ departments following episodes of ERM in the previous 4 weeks, we estimate that there were 53 (95\% confidence interval:29,77) such episodes per 1000 population aged 16-65 per year in the two areas.
This is equivalent to approximately 1.5 million attendances per year nationally. This surprisingly high figure is approximately confirmed by the LASS data $^{8}$ which shows that there were about $1.5 \mathrm{~m}$ attendances at $\mathrm{A}$ and $\mathrm{E}$ departments nationally following leisure accidents in 6 (summer) months of 1987. Of attendances following an incident in a known activity for persons of known age in the LASS data, 27\% occurred in persons aged 15-64 following 'sport' and a further $11 \%$ following walking, running or cycling. These figures suggest that there may be 1.1 million attendances following incidents resulting in ERM per year in persons aged 15-64.

Our pilot study results indicate that $A$ and $E$ attendances represent only $28 \%$ (21/76) of all restrictive injury episodes. This suggests, firstly, that there may be 4-5 million restrictive injury episodes per year in England and Wales, and secondly that the numerous published reports on the epidemiology of sports injuries which have been based on figures from $\mathrm{A}$ and $\mathrm{E}$ departments and sports injury clinics may be very misleading.

\section{Acknowledgements}

We are indebted to the Sports Council who have funded this pilot study and the main study which is currently under way. The success of the pilot study was largely due to the high degree of co-operation and assistance received from the FPCs and local medical committees. We are very grateful to them.

The Medical Care Research Unit is funded by the Department of Health and Trent Regional Health Authority. The views in this paper, however, are those of the authors alone.

\section{References}

1 The General Household Survey. Series GHS No. 15. London: HMSO, 1986.

2 Stephens T. Secular trends in physical activities: fitness boom or bust? Res Q Exerc Sport 1987; 58 (2): 94-105.

3 Fentem PH, Bassey EKJ, Turnbull NB. The New Case for Exercise. London: The Sports Council and the Health Education Authority, 1988.

4 Morris JN, Pollard R, Everitt MG, Chave SPW. Vigorous exercise in leisure time: protection against coronary heart disease. Lancet 1980; ii: 1207-10.

5 Siscovick DS, Laporte RE, Newman JM. The disease-specific benefits and risks of physical activity and exercise. Public Health Rep 1985; 100 (2): 180-8.

6 Taylor CB, Sallis JF, Needle R. The relation of physical activity and exercise to mental health. Public Health Rep 1985; 100 (2): 195-202.

7 Szabadi E. Physical exercise and mental health. Br Med J 1988; 296: 659-60.

8 The Department of Trade and Industry. Home and Leisure Accident Research. Eleventh Annual Report: Home Accident Surveillence System, - 1987 Data. London: Consumer Safety Unit, Department of Trade and Industry, 1989.

9 Koplan JP, Siscovick DS, Goldbaum GM. The risks of exercise: a public health view of injuries and hazards. Public Health Rep 1985; 100 (2): 189-95.

10 Wilson $P$, Elliot $D$. An evaluation of the postcode address file as a sampling frame and its use within OPCS. $J R$ Static Soc Series A, 1987; 150 (3): 230-40.

11 Bale J. Sport and Place. London: Hurst and Co, 1982. 